\title{
Circulating Lipocalin-2 Levels Are Associated With Soluble Lectin-Like Oxidized Low-Density Lipoprotein Receptor-1 Levels In Type 2 Diabetic Patients
}

\author{
Banu Sarer Yurekli ${ }^{*}$, Gokcen Unal Kocabas ${ }^{2}$, Cem Mirili $^{2}$, Asli Suner ${ }^{3}$, Murat Aksit ${ }^{4}$, Ismail Yurekli ${ }^{5}$, \\ Nilufer Ozdemir Kutbay ${ }^{1}$, Ilgin Yildirim Simsir ${ }^{1}$, Giray Bozkaya ${ }^{4}$ \\ ${ }^{1}$ Ege University Faculty of Medicine, Department of Endocrinology, Izmir, Turkey \\ ${ }^{2}$ Bozyaka Education and Research Hospital, Department of Internal Medicine, Izmir, Turkey \\ ${ }^{3}$ Ege University Faculty of Medicine, Department of Biostatistics, Izmir, Turkey \\ ${ }^{4}$ Bozyaka Education and Research Hospital, Department of Biochemistry, Izmir, Turkey \\ ${ }^{5}$ Izmir Ataturk Education and Research Hospital, Department of Cardivascular Surgery, Izmir Turkey
}

\begin{abstract}
Received: September 24,2018; Accepted: October 01,2018; Published: October 02,2018
*Corresponding author : Banu Sarer Yurekli, Ege University Faculty of Medicine, Department of Endocrinology, Ankara Street, Bornova, Izmir, Turkey, 35100,Tel: +90 5055250373;Fax: +902323247880;E-mail: bsareryurekli@yahoo.com
\end{abstract}

\section{Abstract}

Purpose: Diabetes mellitus is associated with atherosclerotic and cardiovascular diseases. Our aim was to investigate the levels of lipocalin-2 (LCN-2) and soluble Lectin-like oxidized low-density lipoprotein receptor-1(sLOX-1) levels in both diabetics and prediabetic with comparison to non-diabetic subjects. We also examined the association of LCN-2 with sLOX-1 and albuminuria

Methods: One hundred forty-two subjects with type 2 diabetes mellitus, 32 prediabetic subjects, 58 non-diabetic controls were consecutively enrolled in this study. LCN-2 and sLOX-1 levels were measured with ELISA assays.

Results: LCN-2 levels didn't show significant difference between diabetics, prediabetic and control groups $(p=0.864)$. sLOX-1 levels were significantly lower in diabetic group $(2.53 \mathrm{ng} / \mathrm{mL}$, median) compared with prediabetic $(2.84 \mathrm{ng} / \mathrm{mL}$, median; $\mathrm{p}=0.041)$ and control groups $(3.00 \mathrm{ng} / \mathrm{mL}$, median; $p=0.001)$. Multiple linear regression analysis showed that urinary albumin excretion and sLOX1 were independently associated with $\mathrm{LCN}-2$. When logistic regression analysis was performed LCN-2 was independent factor determining albuminuria ( $\mathrm{p}=0.021$; OR, 1.001; (1.000-1.001) 95\% CI).

Conclusion: Our study provides the first clinical evidence demonstrating serum LCN-2 concentrations are independently associated with sLOX-1 levels which were found to be lower in type 2 diabetics unexpectedly. LCN-2 was also associated with albuminuria.

\section{Introduction}

Diabetes mellitus is associated with atherosclerotic and cardiovascular diseases. Atherosclerosis is a state of chronic vascular inflammation. Some molecules are associated with increased risk of atherosclerosis in diabetes [1]. Lipocalin-2 (LCN-2), also known as neutrophil gelatinase-associated lipocalin (NGAL), is a glycoprotein stored in human neutrophils [2]. LCN-2 is firstly isolated from mouse kidney cells and afterwards isolated in humans in 1993 [2]. Besides neutrophils, LCN-2 is expressed in other tissues like liver, kidney, adipocytes and macrophages [3]. LCN-2 has a bacteriostatic action which leads LCN-2 to take place in immune response [4]. LCN-2 is also known as an adipokine secreted from adipose tissue [5]. LCN-2 expression is induced by some pro- and anti-inflammatory cytokines like lipopolysaccharide, interleukin (IL)-1ß, IL-6, IL-7, Tumor necrosis factor-alpha (TNF-alpha) [4].

Lectin-like oxidized low-density lipoprotein receptor-1 (LOX-1) mainly expressed by endothelial cells, macrophages and vascular smooth cells is the receptor which mediates oxidized LDL activity in vascular endothelial cells [6]. Soluble lectin-like oxidized low-density lipoprotein receptor-1 (sLOX-1), the soluble form of LOX-1 which is proteolytically cleaved can be measured in serum $[7,8]$. LOX-1 is induced by oxidized LDL (oxldl), shear stress, inflammatory cytokines and angiotensin II (AGII) [9]. Studies in the literature pointing to SLOX-1 levels were higher in acute coronary syndrome (ACS) suggested that circulating sLOX1 levels were an useful marker for early diagnosis of ACS $[10,11]$. Oberoi et al. [4] found that LCN-2 increased the expression of scavenger LOX-1 and induced conversion of macrophages to foam cells in vitro, so indicating that LCN-2 plays an important role in plaque development. This finding encouraged us to search for the relationship of LCN-2 with sLOX-1. They also figured out that LCN-2 levels were higher in subjects with coronary artery disease (CAD) as in the literature $[12,13]$. Besides, LCN-2 was found to be early biomarker for diabetic nephropathy [14]. While Huang Y. Et al. [15] showed that increased LCN-2 levels were independently associated with impaired glucose metabolism and type 2 diabetes, LCN-2 levels were demonstrated to be reduced in type 2 diabetics with long duration diabetes in the study of Chesnaye et al. [16].

Our aim was to investigate the levels of LCN-2 and SLOX-1 levels in both diabetics and prediabetic whom reflect different 
degree of beta cell dysfunction with comparison to non-diabetic subjects. We also examined the association of LCN-2 with sLOX-1, albuminuria and with other metabolic and laboratory parameters in diabetic subjects.

\section{Material and Methods}

\section{Subjects}

The subjects for this study were recruited at the Endocrinology Outpatient Clinic in Izmir Bozyaka Education and Research Hospital. One hundred forty-two subjects with type 2 diabetes mellitus (DM), 32 prediabetic subjects, 58 non-diabetic controls were consecutively enrolled in this study over 12 months. Data were collected as defined previously in the study of Yurekli et al [17]. Informed consent was taken from each subject and local ethic committee approval from Izmir Bozyaka Education and Research Hospital Ethic Committee with "decision number 8" was obtained.

The diagnosis of type 2 diabetes and prediabetes was made according to the American Diabetes Association (ADA) recommendations [18]. prediabetes was defined as either impaired glucose tolerance and/or impaired fasting glucose. Subjects in the control group were non-diabetic according to $75 \mathrm{~g}$ oral glucose tolerance test with the result of normal carbohydrate tolerance.

Detailed medical history was recorded and physical examination was performed for each subject. Height (m) and weight $(\mathrm{kg})$ were measured under fasting conditions. Body mass index (BMI) was calculated as the body weight in kilograms divided by the square of the height in meters $(\mathrm{kg} /$ $\mathrm{m} 2$ ). Hypertension was defined as systolic blood pressure (SBP) $\geq 140 \mathrm{mmHg}$, diastolic blood pressure (DBP) $\geq 90 \mathrm{mmHg}$ or current use of antihypertensive medication. Dyslipidemia is defined as serum total cholesterol levels are $\geq 200 \mathrm{mg} / \mathrm{dL}$; serum triglyceride levels are $\geq 150 \mathrm{mg} / \mathrm{dL}$; serum low density lipoprotein cholesterol (LDL-c) levels are $\geq 130 \mathrm{mg} / \mathrm{dL}$; serum high density lipoprotein cholesterol (HDL-c) levels are $<40 \mathrm{mg} /$ $\mathrm{dL}$ for male, $<50 \mathrm{mg} / \mathrm{dL}$ for female subjects or if there is use of statin treatment for dyslipidemia [19]. Ankle systolic blood pressure was measured on posterior tibial arteries by using hand-held Doppler. After 10 minutes of rest, systolic blood pressure was measured by wrapping sphygmomanometer cuff around each of the two ankles and wrists, respectively. Anklebrachial index (ABI) was calculated as the highest ankle systolic pressure divided by the highest brachial systolic pressure in each patient. $\mathrm{ABI}$ is an easy and noninvasive method for screening of atherosclerosis [20]. While ABI measurement $<0.9$ indicates peripheral arterial disease, $A B I$ value $\geq 1.4$ is indicative for the arterial stiffness [21,22]. Albuminuria was defined as the urinary albumin excretion (UAE) greater than $30 \mathrm{mg} / 24 \mathrm{~h}$. Retinopathy was diagnosed according to examination of ophthalmologist if one of the following findings were present: retinal hemorrhage, hard exudates, new vessels, microaneurysm, and macular edema. Neuropathy examination was performed. Cardiovascular events were based on the history of stroke, coronary artery disease or transient ischemic attack. Patients with coronary heart disease are documented by at least one of the following: previous myocardial infarction, previous percutaneous coronary intervention (PCI) or coronary-artery bypass grafting (CABG) or multivessel coronary artery disease.

\section{Laboratory Examination}

Blood samples were drawn into $8 \mathrm{ml}$ tube gel seperated (Vacuette, Greiner Bio-One, Austria) after 10 hour fast. Blood samples were centrifuged at $3000 \mathrm{rpm}$ for 10 minutes. All serum samples were kept in a freezer at $-800 \mathrm{C}$. Biochemical parameters including fasting blood glucose, total cholesterol, triglyceride, HDL- (high-density lipoprotein) cholesterol, LDL-(low-density lipoprotein) cholesterol, CRP (C-reactive protein), fibrinogen, uric acid, hemoglobin were measured. HbA1c was measured by high performance liquid chromotography (HPLC). A 24-h urine collection was performed for the determination of UAE. Immunoturbidimetric method was used for this measurement. Glomerular filtration rate was calculated according to The Modification of Diet in Renal Disease Study (MDRD) equation $($ eGFR $(\mathrm{ml} / \mathrm{min} / 1.73 \mathrm{~m} 2)=186 \times$ (serum creatinine)-1.154 $\mathrm{x}$ age$0.203 \times 0.742$, if female) [23].

LCN-2 and sLOX-1 were measured by sandwich ELISA method with the commercial assays (LZ, Shanghai, China). Measurement was performed according to user guide. Spectrophotometric measurement was done by using Thermo Scientific Multiscan GO model ELISA reader (Finland) at $450 \mathrm{~nm}$ wavelength. Results for LCN-2 and sLOX-1 were defined as $\mathrm{ng} / \mathrm{L}$ and as $\mathrm{ng} / \mathrm{mL}$, respectively.

\section{Statistical analysis}

Statistical analysis was performed by using IBM Statistical Package of Social Science (SPSS Inc, USA) version 21.0. The Shapiro-Wilk test was used to check distribution patterns of variables. According to the variable distribution, one-way ANOVA followed by Bonferroni's post-hoc comparison test or Kruskal Wallis test followed by Mann-Whitney $U$ test for more than two independent groups were used. Student's t test or MannWhitney U test were used for comparison of two independent groups. Categorical variables were compared by the Chi-square test. Correlation analyses were performed using Spearman's correlation coefficient. Multiple linear regression analysis was performed to identify independent relationships between LCN-2 levels and BMI, SBP, DBP, UAE, sLOX-1. To examine the independent association of albuminuria with the LCN-2, age, gender; we calculated odds ratio (OR) with multivariate logistic regression analysis. Normally distributed data were expressed as mean \pm standard deviation, or as median (min-max) otherwise. A p-value of less than 0.05 was accepted as statistically significant.

\section{Results}

Type 2 diabetic subjects with mean duration of $121.6 \pm$ 92.3 months $(n=142)$, subjects with prediabetic $(n=32)$ and 58 non-diabetic control subjects were recruited for this study. The features of diabetic subjects as far as vascular complications were concerned as follows: Twenty-six \% of diabetic subjects $(n=37)$ had only micro vascular complications, $7.7 \%(n=11)$ had only macro vascular complications, $16.1 \%(n=23)$ had both microand macro vascular complications together. While 61 subjects 


\begin{tabular}{|c|c|c|c|c|}
\hline Variables & $\begin{array}{c}\text { Diabetes } \mathrm{n}=142 \text { mean } \pm \mathrm{SD} \\
\text { median(min-max) }\end{array}$ & $\begin{array}{c}\text { Prediabetes } \mathrm{n}=32 \text { mean } \pm \mathrm{SD} \\
\text { median (min-max) }\end{array}$ & $\begin{array}{c}\text { Control } \mathrm{n}=58 \text { mean } \pm \mathrm{SD} \\
\text { median(min-max) }\end{array}$ & ${ }^{*}$ p value \\
\hline Age (years) & $54.7 \pm 8.654(33-76)$ & $53.8 \pm 9.554(34-74)$ & $53.0 \pm 9.5(30-73)$ & 0.445 \\
\hline Sex (female/male) & $101 / 41$ & $31 / 1$ & $54 / 4$ & $<0.001^{*}$ \\
\hline Hypertension & $30.20 \%$ & $9.30 \%$ & $25.80 \%$ & $<0.001^{*}$ \\
\hline Smoking & $29.50 \%$ & $9.30 \%$ & $20.60 \%$ & 0.603 \\
\hline Body weight (kg) & $\begin{array}{c}80.8 \pm 14.080 \\
(49-118)\end{array}$ & $\begin{array}{c}85.3 \pm 16.083 \\
(61-138)\end{array}$ & $\begin{array}{c}78.0 \pm 13.076 \\
(53-111)\end{array}$ & 0.15 \\
\hline BMI (kg/m2) & $\begin{array}{c}30.5 \pm 4.730 .0 \\
(20.0-43.0)\end{array}$ & $\begin{array}{c}33.3 \pm 6.331 .5 \\
(24.0-57.0)\end{array}$ & $\begin{array}{c}30.8 \pm 5.130 .4 \\
(22.0-43.0)\end{array}$ & 0.06 \\
\hline FBG $(\mathrm{mg} / \mathrm{dL})$ & $\begin{array}{c}157.0 \pm 60.9134 .5 \\
(69-443)\end{array}$ & $\begin{array}{c}109.4 \pm 8.6108 .5 \\
(91-123)\end{array}$ & $\begin{array}{c}94.2 \pm 6.394 \\
(83-99)\end{array}$ & $<0.001^{*}$ \\
\hline HbA1c (\%) & $\begin{array}{l}7.9 \pm 1.67 .6 \\
(5.4-13.0)\end{array}$ & $\begin{array}{c}5.9 \pm 0.385 .9 \\
(5.2-6.6)\end{array}$ & $\begin{array}{c}5.75 \pm 0.455 .7 \\
(5.2-5.8)\end{array}$ & $<0.001 *$ \\
\hline $\mathrm{TC}(\mathrm{mg} / \mathrm{dL})$ & $190.2 \pm 44.0187(112 .-350)$ & $\begin{array}{c}205.1 \pm 33.7201 \\
(146-263)\end{array}$ & $\begin{array}{c}220.5 \pm 47.4210 \\
(148-367)\end{array}$ & $<0.001^{*}$ \\
\hline TG (mg/dL) & $\begin{array}{c}164.6 \pm 98.3141 \\
(49-690)\end{array}$ & $\begin{array}{c}161.4 \pm 64.6140 \\
(69-330)\end{array}$ & $\begin{array}{c}139.0 \pm 55.7132 \\
(57-330)\end{array}$ & $<0.001^{*}$ \\
\hline HDL-C (mg/dL) & $\begin{array}{c}48.3 \pm 13.147 \\
(20-90)\end{array}$ & $\begin{array}{c}47.4 \pm 11.445 \\
(23-78)\end{array}$ & $\begin{array}{c}55.7 \pm 11.554 .5 \\
(29-83)\end{array}$ & $<0.001^{*}$ \\
\hline LDL-C (mg/dL) & $119.3 \pm 39.2118 .5(51-248)$ & $\begin{array}{c}138.8 \pm 27.7139 \\
(80-190)\end{array}$ & $\begin{array}{c}147.2 \pm 41.6138 \\
(83-290)\end{array}$ & $<0.001^{*}$ \\
\hline SBP (mmHg) & $\begin{array}{l}139.4 \pm 21.6140 \\
\quad(90-220)\end{array}$ & $\begin{array}{c}144.3 \pm 22.8140 .0 \\
(110-210)\end{array}$ & $\begin{array}{c}137.8 \pm 19.8140(100- \\
190)\end{array}$ & 0.475 \\
\hline DBP (mmHg) & $\begin{array}{c}82.9 \pm 11.180 \\
(60-120)\end{array}$ & $\begin{array}{c}90.3 \pm 14.885 \\
(70-130)\end{array}$ & $\begin{array}{c}83.1 \pm 10.280 \\
(60-120)\end{array}$ & $0.029 *$ \\
\hline Ankle SBP (mmHg) & $\begin{array}{c}181.6 \pm 33.0180 \\
(90-280)\end{array}$ & $\begin{array}{c}192.5 \pm 40.6180 \\
(140-280)\end{array}$ & $\begin{array}{l}175.0 \pm 37.2180 \\
(90-280)\end{array}$ & 0.106 \\
\hline ABI & $\begin{array}{c}1.31 \pm 0.221 .23 \\
(0.85-2.00)\end{array}$ & $\begin{array}{c}1.34 \pm 0.281 .33 \\
(0.93-2.33)\end{array}$ & $\begin{array}{c}1.26 \pm 0.201 .28 \\
(0.64-1.91)\end{array}$ & 0.289 \\
\hline Creatinine & $\begin{array}{c}0.79 \pm 0.700 .7 \\
(0.5-2.0)\end{array}$ & $\begin{array}{c}0.78 \pm 0.230 .75 \\
(0.5-1.7)\end{array}$ & $\begin{array}{c}0.72 \pm 0.140 .7 \\
(0.5-1.1)\end{array}$ & 0.34 \\
\hline GFR (mL/min) & $\begin{array}{c}109.5 \pm 29.1110 \\
(37-166)\end{array}$ & $\begin{array}{c}136.0 \pm 9.89136 \\
(129-143)\end{array}$ & $\begin{array}{c}128.0 \pm 31.1128 \\
(106-150)\end{array}$ & 0.288 \\
\hline CRP (mg/dL) & $\begin{array}{c}0.50 \pm 0.320 .33 \\
(0.31-1.94)\end{array}$ & $0.60 \pm 0.470 .33(0.31-2.01)$ & $\begin{array}{c}0.52 \pm 0.35(0.31 \\
(0.31-1.65)\end{array}$ & 0.647 \\
\hline Fibrinogen (mg/dL) & $306.3 \pm 70.0296 .3(162.8-529.1)$ & $\begin{array}{c}306.8 \pm 92.1285 .6(2 * 3.8- \\
627.2)\end{array}$ & $\begin{array}{c}311.4 \pm 64.2 \\
(312.1(211.9-468.4)\end{array}$ & 0.587 \\
\hline Uric acid (mg/dL) & $\begin{array}{c}5.2 \pm 1.544 .9 \\
(2.3-11.3)\end{array}$ & $\begin{array}{l}5.3 \pm 1.145 .2 \\
(2.6-7.6)\end{array}$ & $\begin{array}{l}5.0 \pm 1.135 .0 \\
(3.0-7.7)\end{array}$ & 0.534 \\
\hline LCN-2 (ng/L) & $1569.3 \pm 759.71310 .0(179.0-3720.0)$ & $\begin{array}{c}1667.6 \pm 871.71300 .0(876.0- \\
3720.0)\end{array}$ & $\begin{array}{c}1646.2 \pm 864.41245 .0 \\
(756.0-3670.0)\end{array}$ & 0.864 \\
\hline sLOX-1 (ng/mL) & $\begin{array}{c}3.25 \pm 1.992 .53 \\
(0.84-9.89)\end{array}$ & $\begin{array}{c}3.81 \pm 2.122 .84 \\
(1.97-9.95)\end{array}$ & $\begin{array}{c}4.31 \pm 2.723 .0 \\
(1.77-9.97)\end{array}$ & $0.002^{*}$ \\
\hline \multicolumn{5}{|c|}{${ }^{*} \mathrm{p}<0.05$ is significant } \\
\hline \multicolumn{5}{|c|}{ Values are expressed as mean $\pm \mathrm{SD}$ and as median (min-max). } \\
\hline
\end{tabular}

Citation: Yurekli BS, Kocabas GU, Mirili C, Suner A, Aksit M, etal. (2018) Circulating Lipocalin-2 Levels Are Associated With Soluble Lectin-Like Oxidized Low-Density Lipoprotein Receptor-1 Levels In Type 2 Diabetic Patients. J Endocrinol Diab. 5(5): 1-7. DOI: 
were on insulin therapy ( $\mathrm{n}=15$-oral antidiabetic (OAD) plus basal insulin, $\mathrm{n}=46$-multiple insulin injections), 75 of the diabetic subjects were using OAD medication. Six subjects were only on diabetic diet. Demographic, clinical and laboratory features of the diabetic, prediabetic subjects and non-diabetic controls were presented in Table 1.

For LCN-2 levels, there was no significant difference between diabetics, prediabetic and control groups $(1301 \mathrm{ng} / \mathrm{L}, 1300 \mathrm{ng} / \mathrm{L}$, $1245 \mathrm{ng} / \mathrm{L}$, as median, respectively) ( $\mathrm{p}=0.864)$. sLOX-1 levels were significantly lower in diabetic group $(2.53 \mathrm{ng} / \mathrm{mL}$, median $)$ compared with prediabetic $(2.84 \mathrm{ng} / \mathrm{mL}$, median; $\mathrm{p}=0.041)$ and control groups ( $3.00 \mathrm{ng} / \mathrm{mL}$, median; $\mathrm{p}=0.001)$. LCN-2 and sLOX1 levels were not different in diabetic patients with and without vascular complications ( $p=0.445$ and $p=0.235$, respectively). LCN-2 and sLOX-1 had no statistically significant change between diabetic patients with $\mathrm{ABI}$ value $\leq 1.3$ and with $\mathrm{ABI}$ value $>$ 1.3. While sLOX-1 levels were not different in diabetic patients according to glucose control (HbA1c $\leq \% 7$ and $>\% 7$ ), LCN-2 levels were significantly lower at border in diabetic patients with HbA1c $\leq \% 7$ compared with diabetic patients with HbA1c $>\% 7$ (1280 ng/L and $1340 \mathrm{ng} / \mathrm{L}$, median, respectively; $\mathrm{p}=0.045$ ).

When we subtracted subjects who use statin antihyperlipidemic therapy, analysis showed that sLOX-1 levels were still significantly different between diabetic $(n=84)$, prediabetic $(n=26)$ and control $(n=52)$ groups $(\mathrm{p}=0.002)$.

LCN-2 was positively correlated with BMI ( $p=0.029, r=$ $0.183)$, SBP ( $p=0.007, r=0.230)$, DBP ( $p=0.002, r=0.262)$, UAE $(\mathrm{p}=0.002, \mathrm{r}=0.269)$ and sLOX-1 $(\mathrm{p}<0.001, \mathrm{r}=0.435)$ in diabetic group analysis (Table 2). sLOX-1 was also associated with SBP positively in diabetic group $(\mathrm{p}<0.001, \mathrm{r}=0.325)$.

Multiple linear regression analysis was performed in diabetic group to verify independent associations between $\mathrm{LCN}-2$ and BMI, SBP, DBP, UAE and SLOX-1. UAE and sLOX-1 were independently associated with LCN-2 (Table 2).

Table 2: Spearman correlation analysis and multiple regression analysis for Lipocalin-2

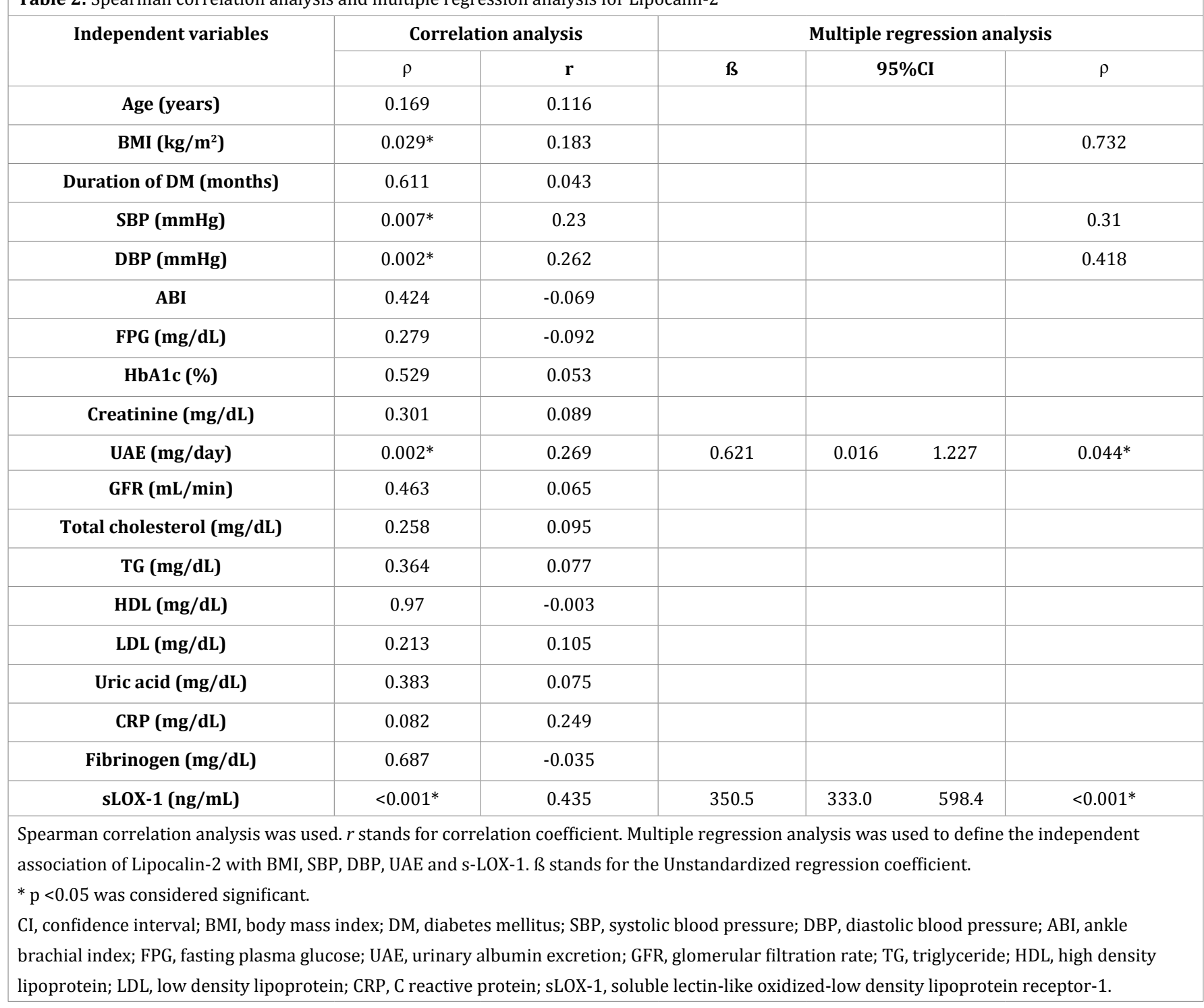

Citation: Yurekli BS, Kocabas GU, Mirili C, Suner A, Aksit M, etal. (2018) Circulating Lipocalin-2 Levels Are Associated With Soluble Lectin-Like Oxidized Low-Density Lipoprotein Receptor-1 Levels In Type 2 Diabetic Patients. J Endocrinol Diab. 5(5): 1-7. D0I: 
LCN-2 levels were significantly higher in diabetic subjects with albuminuria $(\mathrm{n}=14)(1840 \mathrm{ng} / \mathrm{L}$, median) when compared with diabetic subjects without albuminuria $(n=113)(1496 \mathrm{ng} / \mathrm{L}$, median $)(p=0.004)$.
When logistic regression analysis was performed for each independent variables as duration of diabetes, $\mathrm{HbA1c}, \mathrm{ABI}$, dyslipidemia, HT, gender, age, sLOX-1, LCN-2 individually; gender, age and LCN-2 were found to be factors affecting albuminuria. When the model was set up for those three independent variables, LCN-2 was independent factor determining albuminuria ( $\mathrm{p}=$ 0.021; OR, 1.001; (1.000-1.001) 95\% CI) (Table 3).

Table 3. Logistic regression models predicting albuminuria for diabetic patients.

\begin{tabular}{|c|c|c|c|c|c|c|}
\hline \multirow{2}{*}{ Independent variables } & \multicolumn{3}{|c|}{ Single variables 1} & \multicolumn{3}{|c|}{ Final model2 } \\
\hline & OR & 95\% CI & p value & OR & 95\% CI & $p$ value \\
\hline Duration of diabetes & 1.003 & 0.997-1.009 & 0.342 & - & - & - \\
\hline HbA1c & 0.947 & $0.664-1.349$ & 0.762 & - & - & - \\
\hline ABI & 0.231 & $0.014-3.750$ & 0.303 & - & - & - \\
\hline Dyslipidemia & 1.37 & $0.285-6.584$ & 0.695 & - & - & - \\
\hline HT & 0.356 & $0.889-12.675$ & 0.074 & - & - & - \\
\hline Gender & 3.375 & $1.085-10.499$ & $0.036^{*}$ & 2.827 & $0.847-9.441$ & 0.091 \\
\hline Age & 1.079 & $1.006-1.156$ & $0.032^{*}$ & 1.069 & $0.993-1.150$ & 0.075 \\
\hline Lipocalin-2 & 1.001 & $1.000-1.001$ & $0.007^{*}$ & 1.001 & $1.000-1.001$ & $0.021^{*}$ \\
\hline \multicolumn{7}{|c|}{$\begin{array}{l}{ }^{1} \text { was univariate logistic regression model on single variables. }{ }^{2} \text { was final multiple logistic regression model in backward stepwise method on } \\
\text { variables found significant in model on single variables included together in the model. } \\
\text { OR: odds ratio } \\
{ }^{*} p \text { value of }<0.05 \text { was considered significant }\end{array}$} \\
\hline
\end{tabular}

\section{Discussion}

We have figured out that there was no significant difference between LCN-2 levels of study groups. sLOX-1 levels were found to be lower in diabetics when compared with prediabetic and control groups. It was demonstrated for the first time that LCN-2 levels were associated with sLOX-1 levels. Besides, LCN-2 was the independent predictor of albuminuria in type 2 diabetics.

Tan et al. [6] showed for the first time that sLOX-1 levels were elevated in type 2 diabetes and it was associated with advanced glycation end products (AGEs). This finding was supported by the in vitro study in which glucose and ages increased the level of sLOX-1 in conditioned medium of cultured endothelial cells. They suggested that increased sLOX-1 may add to endothelial dysfunction. On the contrary to the literature, we found slox1 levels as lower in diabetic group compared to prediabetics and non-diabetics. We may hypothesize that SLOX-1 may be regulated by parameters other than glucose. As we did not record antihypertensive medication use as a limitation of the study, we could not be able to analyze sLOX-1 levels in subjects according to use of renin-angiotensin system blockade drugs. Because, angiotensin II increases sLOX-1 expression, Tan et al. [6] observed that diabetic subjects receiving angiotensin-converting enzyme inhibitor or angiotensin II receptor antagonist had significantly lower serum sLOX-1 levels than subjects who were not on those medications. In our study, the type of OAD or diabetes treatment (OAD/insulin) did not affect the sLOX-1 levels significantly (data not shown). As an another explanation for our findings regarding to the low levels of sLOX-1 in diabetics, we may speculate that post-translational process to secret slox- 1 into circulation may not be working well in the diabetic subjects. The levels of oxldl may have been explaining the exact relationship between sLOX1, LOX-1 and oxldl. But unfortunately, we could not measure the levels of oxldl in our study.

When we analyzed the diabetic subjects according to the presence of micro and/or macro vascular complications, sLOX-1 levels did not show any significant difference in diabetic subjects with/without vascular complications. Opposed to the study of Tan et al. [6], sLOX-1 levels did not differ between diabetic patients with better and worse glucose control (hba1c $\leq 7 \%$ vs. $>7 \%$ ). When the subjects using statin therapy were excluded, sLOX-1 levels significantly remained low in diabetic subjects when compared to prediabetic and non-diabetics.

Lubrano et al. [24] figured out that sLOX-1 levels were associated with inflammatory markers like TNF-alpha, IL-6, C reactive protein (CRP) in atherosclerotic subjects. He observed that sLOX-1 levels were higher in more severe atherosclerotic patients compared to subjects with milder atherosclerotic lesions. In another study, sLOX-1 levels were higher in type 2 diabetics with peripheral arterial disease (PAD) than without PAD and sLOX-1 levels were found to be negatively associated with ABI [25]. sLOX-1 levels were not found to be associated with ABI in our study. Brinkley et al. [26] found that slox-1 levels were higher in obese postmenopausal women compared to lean ones and sLOX-1 levels were associated with BMI. In our study, sLOX-1 
levels were not associated with BMI, it was found to be associated with SBP and LCN-2 levels.

We demonstrated that LCN-2 levels were not different between type 2 diabetes, prediabetic and control groups. Eilenberg W et al. [28] found that LCN-2 levels were higher in diabetics with carotid artery stenosis compared to non-diabetic group. LCN-2 mRNA was detectable in 95\% of analyzed carotid artery lesions of diabetics compared to $5 \%$ of non-diabetics ( $p<0.0001$ ). Supporting this finding, Hemdahl AL et al. [28] showed that LCN-2 expression was increased in atherosclerotic plaques. Eilenberg $\mathrm{W}$ et al. [27] also showed that diabetics under metformin treatment had significantly lower LCN-2 levels compared to non-diabetics. We only found that LCN-2 levels were lower in diabetic patients with better glycemic control compared to those with worse glycemic control based on hba1c (hba1c $\leq 7 \%$ vs. $>7 \%)(p=0.045)$. So, in our study antidiabetic treatment may be altering the LCN-2 levels. As opposed to our study, Elkhidir AE et al. [29] observed that LCN-2 levels were increased in type 2 diabetics compared with non-diabetic controls and LCN-2 levels didn't differ significantly between controlled and uncontrolled diabetes [29]. While, LCN-2 was not correlated with BMI in the study of Elkhidir AE [29], in our study LCN-2 was associated with BMI, SBP, DBP, UAE, sLOX-1 levels in correlation analysis but multiple regression analysis showed that SLOX-1 and UAE were independent predictors of LCN-2 levels in diabetics.

Oberoi et al. [4] investigated proatherosclerotic effect of LCN2 on murine macrophages and showed that LCN-2 induced foam cell formation leading to atherosclerotic plaque development. They also observed that LCN-2 induced LOX-1 receptors in macrophages. As a supporting finding to this, we showed for the first time that LCN-2 levels were positively associated with sLOX1 levels in type 2 diabetic patients. So, although LCN-2 levels were not different between diabetics and control groups, LCN-2 was independently associated with SLOX-1.

It was demonstrated that there is significant association between LCN-2 and diabetic complications. Serum and urinary LCN-2 have been used as early marker of renal involvement in type 2 diabetic patients [30]. Motawi et al. [14] showed that LCN2 levels were increased in type 2 diabetics with microalbuminuria compared to control group and also LCN-2 was found to be associated with albuminuria. We also figured out that LCN-2 was independent predicting factor for presence of albuminuria adjusting for other clinical and laboratory parameters according to logistic regression analysis.

Some conflicting findings in the literature point that LCN2 levels were significantly higher in acute coronary syndrome patients compared to subjects with normal coronary arteries [31] , however Giaginis et al. [32] showed a contradictory result in which LCN-2 levels didn't differ between subjects with and without carotid artery stenosis.

Although we didn't study atherosclerotic features specifically in our diabetic patients but we showed the strong correlation of LCN-2 with SLOX-1 which was associated with atherosclerosis.

\section{Conclusion}

Our study provides the first clinical evidence demonstrating serum LCN-2 concentrations are independently associated with sLOX-1 levels which were found to be lower in type 2 diabetics unexpectedly. Further studies are needed to explain the low levels of sLOX-1 in type 2 diabetics regarding to antihypertensive medication and oxLDL, LOX-1 interaction. We demonstrated LCN-2 levels were independent predictor of albuminuria in type 2 diabetics. So, we could speculate that LCN-2 could be used as atherosclerotic marker besides to being renal marker in diabetic nephropathy. Being a cross sectional study is a limitation for our study. Further longitudinal studies would allow us to determine the regulatory factors for $\mathrm{LCN}-2$ and predictive value of $\mathrm{LCN}-2$ for diabetes associated atherosclerosis.

\section{Acknowledgements}

This Work Was Supported By Ege University Scientific Research Project Committee With Project Number Of 2015-TIP043.

\section{Author contribution}

BSY Recruited The Subjects For The Study, Wrote And Critically Edited The Manuscript, GUK And CM Had Recruited The Patients, IY Edited The Manuscript And Also Perfomed English Editing, And Provided Hand Doppler, MA And GB Performed ELISA Studies, AS Had Done Statistical Analysis, NOK And IYS Searched The Literature.

\section{Declarations}

Ethical approval All procedures performed in studies involving human participants were in accordance with the ethical standards of the institutional and/or national research committee and with the 1964 Helsinki declaration and its later amendments or comparable ethical standards. This study was approved by the local ethic committee of Bozyaka Research and Education Hospital.

All procedures performed in studies involving human participants were in accordance with the ethical standards of the institutional and/or national research committee and with the 1964 Helsinki declaration and its later amendments or comparable ethical standards.

Informed consent: Informed consent was obtained from all individual participants included in the study.

\section{References}

1. Berg AH, Scherer PE. Adipose tissue, inflammation, and cardiovascular disease. Circ Res. 2005;96(9):939-949. Doi: 10.1161/01. RES.0000163635.62927.34

2. Kjeldsen L, Johnsen AH, Sengelov H, Borregaard N. Isolation and primary structure of NGAL, a novel protein associated with human neutrophil gelatinase. J Biol Chem. 1993;268(14):10425-10432.

3. Liu $Q$, Nilsen-Hamilton $M$. Identification of a new acute phase protein. J Biol Chem. 1995;270(38):22565-22570.

4. Oberoi R, Bogalle EP, Matthes LA, Schuett H, Koch A-K, Grote K, Schieffer B, Schuett J, Luchtefeld M. Lipocalin (LCN) 2 mediates proatherosclerotic processes and is elevated in patients with coronary 
artery disease. PLoS ONE. 2015;10:e0137924. Doi: 10.1371/journal. pone. 0137924

5. Yan Q-W, Yang Q, Mody N, Graham TE, Hsu C-H, Xu Z, et al. The adipokine lipocalin 2 is regulated by obesity and promotes insulin resistance. Diabetes. 2007;56(10):2533-2540. Doi:10.2337/db07-0007

6. Tan KC, Shiu SW, Wong Y, Leng L, Bucala R. Soluble lectin-like oxidized low density lipoprotein receptor-1 in type 2 diabetes mellitus. J Lipid Res. 2008;49(7):1438-1444. Doi: 10.1194/jlr.M700551-JLR200

7. Yoshida H, Kondratenko N, Green S, Steinberg D, Quehenberger 0. Identification of the lectin-like receptor for oxidized low-density lipoprotein in human macrophages and its potential role as a scavenger receptor. Biochem J 1998;334(Pt 1):9-13.

8. Murase T, Kume N, Kataoka H, Minami M, Sawamura T, Masaki T, Kita T. Identification of soluble forms of lectin-like oxidized LDL receptor-1. Arterioscler Thromb Vasc Biol. 2000;20(3):715-720.

9. Li D, Mehta JL. Upregulation of endothelial receptor for oxidized LDL (LOX-1) by oxidized LDL and implications in apoptosis of human coronary artery endothelial cells: evidence from use of antisense LOX-1 mRNA and chemical inhibitors. Arterioscler Thromb Vasc Biol. 2000;20(4):1116-1122.

10. Hayashida K, Kume N, Murase T Minami M, Nakagawa D, Inada T, Tanaka M, et al. Serum soluble lectin-like oxidized low-density lipoprotein receptor-1 levels are elevated in acute coronary syndrome a novel marker for early diagnosis. Circulation. 2005;112(6):812-818. Doi: 10.1161/CIRCULATIONAHA.104.468397

11. Kume N, Mitsuoka H, Hayashida K, Tanaka M, Kita T. Soluble lectin-like oxidized low-density lipoprotein receptor-1 predicts prognosis after acute coronary syndrome: a pilot study. Circ J. 2010;74(7):1399-1404.

12. Zhao ZW, Zhu XL, Luo YK, Lin CG, Chen LL. Circulating soluble lectin-like oxidized low-density lipoprotein receptor-1 levels are associated with angiographic coronary artery disease. clin cardiol. 2011;34(3):172177. Doi: $10.1002 /$ clc. 20847

13. Sahinarslan A, Kocaman SA, Bas D, Akyel A, Ercin U, Zengin O, et al. Plasma neutrophil gelatinase- associated lipocalin levels in acute myocardial infarction and stable coronary artery disease. Coron Artery Dis. 2011;22(5):333-338. Doi: 10.1097/MCA.0b013e3283472a71

14. Motawi TK, Shehata NI, ElNokeety MM, El-Emady YF. Potential serum biomarkers for early detection of diabetic nephropathy. Diabetes Res Clin Pract. 2018;136:150-158. Doi: 10.1016/j.diabres.2017.12.007

15. Huang Y, Yang Z, Ye Z, Li Q Wen J, Tao X, et al. Lipocalin-2, glucose metabolism and chronic low-grade systemic inflammation in Chinese people. Cardiovasc Diabetol. 2011;11:11. Doi: 10.1186/1475-2840$11-11$

16. De la Chesnaye E, Manuel-Apolinar L, Zarate A, Damasio L, Espino N, Revilla-Monsalve MC, et al. Lipocalin-2 plasmatic levels are reduced in patients with long-term type 2 diabetes mellitus. Int J Clin Exp Med 2015;8(2):2853-2859.

17. Yurekli BS, Kocabas GU, Aksit M, Kutbay NO, Suner A, Yurekli I, et al. The low levels of bone morphogenic protein- 4 and its antagonist noggin in type 2 diabetes. Hormones (Athens). 2018;17(2):247-253. Doi: $10.1007 / \mathrm{s} 42000-018-0041-5$

18. American Diabetes Association. Diagnosis and classification of diabetes mellitus. Diabetes Care. 2015;38:S8-S16.

19. Shen Y, Ma X, Zhou J, Pan X, Hao Y, Zhou M, et al. Additive relationship between serum fibroblast growth factor 21 level and coronary artery disease. Cardiovasc Diabetol. 2013;12:124. Doi: 10.1186/1475-2840$12-124$
20. Bendermacher BL, Teijink JA, Willigendael EM, Bartelink ML, Peters $\mathrm{RJ}$, Langenberg $\mathrm{M}$, et al. Applicability of the ankle-brachial-index measurement as screening device for high cardiovascular risk: an observational study. BMC Cardiovasc Disord. 2012;12:59. Doi: 10.1186/1471-2261-12-59

21. McDermott MM, Greenland P, Liu K, Celic L, Criqui MH, Chan C, et al. The ankle brachial index is associated with leg function and physical activity: the Walking and Leg Circulation Study. Ann Intern Med. 2002;136(12):873-883.

22. Makhdoomi K, Mohammadi A, Yekta Z, Aghasi MR, Zamani N, Vossughian S. Correlation between ankle-brachial index and microalbuminuria in type 2 diabetes mellitus. Iranian J Kidney Dis. 2013;7(3):204-209.

23. National Kidney Foundation. K/DOQI clinical practice guidelines for chronic kidney disease: evaluation, classification, and stratification. Am J Kidney Dis. 2002;39(2 Suppl1):S1-S266.

24.Lubrano V, Del Turco S, Nicolini G, Di Cecco P, Basta G. Circulating Levels of Lectin-Like Oxidized Low-Density Lipoprotein Receptor-1 are Associated with Inflammatory Markers. Lipids. 2008;43:945-950. Doi: 10.1007/s11745-008-3227-9

25. Fukui M, Tanaka M, Senmaru T, Nakanishi M, Mukai J, Ohki M, et al. LOX-1 is a novel marker for peripheral artery disease in patients with type 2 diabetes. Metabolism. 2013;62(7):935-938. Doi: 10.1016/j. metabol.2013.01.018

26. Brinkley TE, Kume N, Mitsuoka H, Phares DA, Hagberg JM. Elevated Soluble Lectin-like Oxidized LDL Receptor 1 (LOX-1) Levels in Obese Postmenopausal Women. Obesity (Silver Spring). 2008;16(6):14541456. Doi:10.1038/oby.2008.213

27. Eilenberg W, Stojkovic S, Piechota-Polanczyk A, Kaider A, Kozakowski N, Weninger WJ, Nanobachvili J, Wojta J, Huk I, Demyanets S, Neumayer C. Neutrophil gelatinase associated lipocalin (NGAL) is elevated in type 2 diabetics with carotid artery stenosis and reduced under metformin treatment. Cardiovasc Diabetol. 2017;16(1):98. Doi: 10.1186/s12933017-0579-6

28. Hemdahl AL, Gabrielsen A, Zhu C, Eriksson P, Hedin U, Kastrup J, et al. Expression of neutrophil gelatinase-associated lipocalin in atherosclerosis and myocardial infarction. Arterioscler Thromb Vasc Biol. 2006;26:136-142. 2006;26(1):136-142. Doi: 10.1161/01. ATV.0000193567.88685.f4

29. Elkhidir AE, Eltaher HB, Mohamed AO. Association of lipocalin-2 level, glycemic status and obesity in type 2 diabetes mellitus. BMC Res Notes. 2017;10:285. Doi: 10.1186/s13104-017-2604-y

30. Bolignano D, Lacquaniti A, Coppolino G, Donato V, Fazio MR, Nicocia G, et al. Neutrophil gelatinase-associated lipocalin as an early biomarker of nephropathy in diabetic patients. Kidney Blood Press Res. 2009;32(9):91-98. Doi: 10.1159/000209379

31. Soylu K, Aksan G, Nar G, Özdemir M, Gülel O, İnci S, et al. Serum neutrophil gelatinase-associated lipocalin levels are correlated with the complexity and the severity of atherosclerosis in acute coronary syndrome. Anatol J Cardiol. 2015;15:450-455. Doi: 10.5152/ akd.2014.5513

32. Giaginis C, Zira A, Katsargyris A, Klonaris C, Theocharis S. Clinical implication of plasma neutrophil gelatinase-associated lipocalin (NGAL) concentrations in patients with advanced carotid atherosclerosis. Clin Chem Lab Med. 2010;48(7):1035-1041. Doi: 10.1515/CCLM.2010.211 